\title{
IMAGENS DA CLASSE TRABALHADORA NO DOCUMENTÁRIO BRASILEIRO: apontamentos metodológicos
}

\author{
Antônio da Silva Câmara* \\ Bruno Vilas Boas Bispo** \\ Rodrigo Oliveira Lessa ***
}

\begin{abstract}
Neste artigo, retomamos aspectos metodológicos de pesquisas sobre representações da classe trabalhadora encontradas no cinema documentário. Através da discussão com base em conceitos de Marx e de outros teóricos, como Lukács, Adorno, Benjamin e Kracauer, procuramos aqui revisar os termos dessa experiência a partir de sua proposta metodológica e aprofundar uma abordagem do conceito de representação que contemple os aspectos de forma e conteúdo do filme como obra de arte. Desse modo, apontamos para a correlação entre a representação e a realidade social, ressaltando a relevância dos elementos criativos a ela intrínsecos. Para tanto, buscamos analisar o filme como produto das determinações resultantes da relação reciprocamente mediada entre artistas e realidade social. Em seguida, buscamos desdobrar tais reflexões em procedimentos específicos de análise, expondo o uso de tais elementos na pesquisa citada, de modo a contribuir para as reflexões metodológicas acerca de uma sociologia estética a partir da experiência acumulada em nossas investigações.

Palavras-chave: Sociologia. Cinema. Cinema documentário. Metodologia. Arte.
\end{abstract}

\section{INTRODUÇÃO}

Neste artigo, retomamos a metodologia da pesquisa sobre as representações da classe trabalhadora no cinema documentário, incorporando novas discussões ${ }^{1}$ e refletindo sobre o que consideramos uma das possíveis vias de estudo do cinema em uma perspectiva sociológica. Partindo das contribuições do materialismo histórico, buscamos construir um conceito de representação que contemple os

\footnotetext{
* Universidade Federal da Bahia. Faculdade de Filosofia e Ciências Humanas. Departamento de Sociologia. Programa de Pós-Graduação em Ciências Sociais.

Estrada de são Lázaro 197. Federação. Cep. 40.210-730. Salvador-Bahia - Brasil. antsilvcamara@gmail.com https://orcid.org/0000-0003-0565-4110

* * Universidade Federal da Bahia. Faculdade de Filosofia e Ciências Humanas.

Estrada de são Lázaro 197. Federacão. Cep. 40.210-730.

Salvador - Bahia - Brasil. bruno.vbb@gmail.com

http://orcid.org/0000-0001-9138-8247

** * Instituto Federal de Educação, Ciência e Tecnologia Baiano (IF Baiano), Campus Alagoinhas.

Rua: Manoel Romão, 150 - Alagoinhas Velha. Alagoinhas -

Bahia - Brasil.rodrigo.ciso@gmail.com

https://orcid.org/0000-0002-8619-5894

${ }^{1}$ Retomamos, aqui, parte das reflexões produzidas no seio do grupo de pesquisa sobre a representação fílmica no cinema documentário em diversos objetos, qual seja do mundo rural, sobre as representações fílmicas em Dziga Vertov, ou ainda em Patrício Guzmán (Bispo, 2019; Lessa, 2015b; Silva, 2017).
}

aspectos de forma e conteúdo da obra. E apontamos para a correlação entre a representação e a realidade social que propiciou a criação da obra de arte, além de assinalar a relevância dos elementos criativos intrínsecos à arte. Para tanto, destacamos o fato de que a obra de arte é fruto do processo criativo do artista em contato com o seu entorno, sobretudo na medida em que apresenta, ao mesmo tempo, elementos da subjetividade criadora e da objetividade social.

As reflexões aqui expostas advêm de investigações que analisaram o caso específico da forma estética presente no cinema documentário e nas representações sobre frações da classe trabalhadora. Dessa forma, são pontualmente recuperadas discussões relativas a quatro filmes documentários que construíram suas narrativas cinematográficas em torno de frações de classe, como servidores públicos, trabalhadores médios urbanos, camponeses, diretores sindicais, migrantes nordestinos, etc., ao tempo em que apresentaram leituras e concepções a respeito de suas condições de vida no contexto social e histórico do país. Foram eles: Viramundo (1965), de Geraldo Sarno, A opinião pública (1967), de Arnaldo Jabor, $A B C$ da Greve 
(1970/1990), ${ }^{2}$ de Leon Hirszman, e Cabra marcado para morrer (1984), de Eduardo Coutinho.

Tais filmes documentários, ao se apropriarem do cotidiano do proletariado brasileiro - levantando questões e reverberando debates políticos e científicos de sua época (Napolitano, 2001, 2014) - alteram as perspectivas da produção documentária, ao atentar para os depoimentos dos personagens, o ponto de vista dos diretores de cinema, na narrativa, e a própria dinâmica de inserção autoral no tempo e no espaço. Assim, novos diretores contribuíram para promover uma transformação bastante profunda na estética desse gênero cinematográfico no Brasil (Xavier, 2014).

Tanto nesses filmes, quanto em outras obras da época, era recorrente o argumento fílmico centrado em personagens e atores sociais da classe trabalhadora que vivenciavam diversas circunstâncias relacionadas ao contexto das relações sociais de produção e da luta de classes. É o que podemos notar a partir dos eventos relacionados à Greve de 1979 no ABC paulista, acompanhados em $A B C$ da greve (1990), ou da repressão das Ligas Camponesas, em Cabra marcado para morrer (1984). A ideia inicial da pesquisa era estudar as relações entre as formas de representação da realidade social da classe trabalhadora no cinema documentário e o quadro de transformações 亏ें e mudanças sociais que teriam influenciado Фं a forma estética desses filmes. Em particular, importava destacar o impacto de novos estii los, técnicas e obras cinematográficas sobre o gênero documentário, a incorporação de discursos ideológicos presentes na arte, na ciên- cia e no senso comum naquele período, e, por fim, como a vida social da classe trabalhadora era representada nos filmes. Tal proposta nos ajudaria a compreender de que maneira essas imagens teriam representado as condições sociais e materiais do proletariado brasileiro através do cinema documentário.

2 Embora tenha sido lançado publicamente apenas em 1990 pela Cinemateca Brasileira, após a morte do seu diretor, ABC da greve teve concluídas as etapas de registro fílmico ainda em 1979 por Leon Hirszman.

\section{MÉTODO DE INVESTIGAÇÃO DA ARTE A PARTIR DE UMA SOCIOLOGIA ESTÉTICA E DIALÉTICA}

\section{A representação como objeto de estudo}

Entendemos a obra de arte, e o filme em particular, como a solução encontrada pelo seu criador para configurar, através de sua subjetividade, as relações sociais concretas (Benjamin, 2014; Casetti, 1999; Jameson, 1999; Kracauer, 2010; Lukács, 1982a). Para Jameson (1999), por exemplo, a obra de arte seria produto da ideologia, fruto da relação entre os condicionantes econômicos e as representações coletivas, partindo o autor da compreensão de que o modo de produção da vida material condiciona o processo da vida política, social e cultural. A ideologia, desse modo, estaria presente nas obras artísticas sob a forma de ideias, desejos e crenças coletivas expressas por meio do imaginário simbólico.

Na reflexão sobre esse condicionamento social e ideológico da arte, contudo, é necessário pontuar o caráter de relativa autonomia que ela não deixa de manter diante do mundo. Entendemos quando Francastel (2015), por exemplo, afirma que, se toda arte denota as necessidades e as aspirações da época em que nasce, através do estudo dessa significação é possível compreender a realidade social. Todavia, sobre esse entendimento, deve-se ponderar, como esclarece Adorno (2008), que, mesmo sofrendo determinações ideológicas, a obra de arte tem, em si, a capacidade ou potencialidade de opor-se ao mundo administrado, O condicionamento social não é, pois, algo que simplesmente aprisiona a forma da arte nos desdobramentos do mundo objetivo, mas a parte de um processo criativo que resulta na forma estética.

A expressão "sociologia estética", por sua vez, foi apresentada, inicialmente, na revista L’Anée Sociologique, e utilizada como elemento classificatório da produção então publicada (Sebbah, 2005). Tal expressão foi assimilada por Bastide (1971), que, em sua obra, indicou a so- 
ciologia estética como uma das possibilidades investigativas da sociologia da arte. Neste artigo, retomamos essa terminologia de modo crítico, pois a vinculamos à possibilidade de análise da obra a partir de uma perspectiva dialética.

Para tal abordagem, buscamos elaborar análises que correlacionem forma e conteúdo, considerando as possibilidades criativas dos artistas em seus contextos históricos. Nossa prática difere, ainda, dos métodos amplamente utilizados nas ciências humanas, como análise do discurso ou análise de conteúdo (Flick; Kardoff; Steinke, 2004) das práticas discursivas, por identificarmos uma especificidade da arte não contemplada por esses recursos analíticos, que não incorporam todas as reflexões elaboradas inicialmente pelo campo da estética e assimilados por sociólogos que desenvolveram pesquisas acerca da obra de arte.

Ao demonstrar a viabilidade dessa possibilidade analítica, Adorno (2008) afirma que forma seria conteúdo condensado. Ainda que com reservas, consideramos que essa expressão corporifica a possibilidade analítica de uma sociologia estética. Partimos, portanto, de uma perspectiva de que a obra de arte apresenta uma dupla condição - Factum Social e autonomia -, contendo elementos de heteronomia e autonomia relativa (Adorno, 2008), ou se apresentando, concomitantemente, como espelho e modelo da sociedade (Casetti; Di Chio, 1991).

Sem nos propormos a avaliar em que medida uma produção é mais ou menos o resultado do gênio artístico ou da transposição mediatizada de traços já estabelecidos das relações sociais, ou ainda que implicações isso teria, o que nossa proposta apresenta como possibilidade é a articulação de um método voltado para o estudo da criação artística e do condicionamento social nela mediatamente manifestado. Ou, o que equivale a dizer: investigar a maneira como a obra de arte carrega consigo, como representação, os indícios da relação mediatizada entre o artista e o mundo objetivo que fizeram parte de seu processo de criação.

Embora não tenha se notabilizado pelo estudo da arte e suas asserções sobre esse objeto sejam esparsas, é no próprio Marx que podemos encontrar os primeiros caminhos para uma reflexão materialista do estudo da arte como representação. Esse autor, no texto da Contribuição À Crítica da Economia Política - mais particularmente quando se refere ao modo como os economistas do século XVI tomavam noções como "população", "nação" e Estado" como realidades concretas -, mostra como as abstrações que realizamos sobre o mundo se apresentem para nós como o que há de mais concreto e imediato, mas elas são apenas representações caóticas do todo. Diferentemente do modo como se apresenta aos olhos daqueles que buscam ali o ponto de partida para seus estudos, Marx (2003) observa que as categorias se encontram obscurecidas para os investigadores, sendo necessário, portanto, através de mediações, isolar as categorias abstratas, de modo a permitir ao pensamento apropriar-se dialeticamente do mundo material, transformando-o ao mesmo tempo em que é transformado por ele.

Por isso, para compreender efetivamente não só as relações materiais de produção, mas também as representações que realizamos sobre o mundo - incluídas aí as que poderemos encontrar nas obras de arte -, seria preciso tomar aquilo que se nos apresenta como abstrações e não como o concreto, dado do imediato, mas como síntese de múltiplas determinações. Tais determinações, por sua vez, só podem ter a sua existência apreendida como unidade do diverso na medida em que se passa a investigar criticamente o processo social e histórico de sua gênese.

Esse é um dos motivos de a mera descrição das passagens dos filmes ou de seus principais momentos, mesmo quando se buscam suas referências no âmbito do cinema, não ser suficiente para a compreensão sociológica do que estamos entendendo como representação. Se observarmos bem, os conteúdos relativos aos conflitos, as formas de expressão e as relações travadas entre os atores sociais presentes 
nos filmes não são apenas questões levantadas pelas obras a partir da linguagem cinematográfica, mas também elos importantes com os fenômenos da realidade social que condicionaram sua realização. A cada oportunidade na qual as temáticas dos filmes são contextualizadas, aproximadas dos fatos e das circunstâncias nas quais a cadeia de seus acontecimentos ocorre, mais transparente se torna sua relação com a sociedade e a história e, ao mesmo tempo, mais aprofundada se torna nossa visão sobre o próprio filme.

Foi a partir dessa orientação que a análise dos filmes nos levou a desenhar o recorte histórico que situou a produção cinematográfica documental no contexto das transformações vividas entre as décadas de 1960, 1970 e 1980. No estudo, destacam-se, em particular, dois períodos históricos fundamentais. Denominamos o primeiro como "Primeira fase do documentarismo brasileiro e o despertar da criticidade cinematográfica". Nesse período, situamos a ascensão das reflexões sobre a cultura como mediação do comportamento dos personagens a partir da emergência do Cinema Novo, etapa caracterizada, sobretudo, a partir das discussões feitas sobre os filmes Viramundo e Opinião pública. O segundo período se configura como "A reabertura política e o deso taque para as lutas sociais no documentário", Бे e nele são analisados $A B C$ da greve e Cabra ¿ marcado para morrer, nos quais recuperamos a emergência de representações sobre as lutas os quais os filmes apontavam, buscando, assim, entender melhor os enredos dos filmes e, consequentemente, os fenômenos sociais e políticos nos quais a classe trabalhadora estava envolvida (Lessa, 2015a).

Ao prosseguir com sua reflexão sobre o método da economia política, Marx (2003) afirma que os indivíduos se apropriam do concreto de variadas formas, dentre as quais, a arte, a ciência, a religião e as atividades práticas. Nesse sentido, a aplicação correta do método dialético significará a apreensão da obra como síntese dos antagonismos e das tensões sociais. Dessa maneira, a representação, na arte, corresponde igualmente ao produto de determinações e processos sociais que se realizam à medida que o ser humano se apropria do mundo para sua reprodução material e espiritual, o que, como escreveu Adorno (2008), faz com que os antagonismos e as tensões sociais - que foram relevantes para a construção da linguagem, como o imaginário, a ideologia, a luta de classes, e toda sorte de questões que dizem respeito à realidade social - se apresentem como problemas imanentes à sua forma, como traços que definem sua relação com a sociedade. "Os antagonismos não resolvidos da realidade retornam às obras de arte como problemas imanentes à sua forma. É isto, e não a trama dos momentos objetivos, que define a sua relação com a sociedade" (Adorno, 2008, p. 18).

Como é possível perceber pela observação de Adorno (2008), se a obra de arte é o objeto de estudo, ela consiste também em um possível ponto de partida para a análise dos antagonismos não resolvidos da realidade. Nesse sentido, embora reconheçamos a relevância de trabalhos que se dedicam a construir "biografias" de obras de arte - reportando-se às circunstâncias nas quais elas foram criadas, para entender a sua recepção diante do público ou da crítica, ou mesmo que se voltem estritamente para uma abordagem dos fatos históricos e questões para as quais ela aponta (Zolberg, 2006) - o estudo de sua representação sob a perspectiva dialética aqui empregada concebe outra possibilidade de produção do conhecimento sociológico. Se, como afirmamos, as 
obras de arte são a síntese das determinações resultantes da relação reciprocamente mediada entre o artista e a realidade social, essa síntese compreende a própria representação exteriorizada, decorrente da unidade entre forma e conteúdo da obra, propiciando, portanto, a possibilidade de o investigador, ao analisá-la, apreender sua própria sociedade.

Também por essa razão, no caso em particular do estudo dos documentários e suas representações sobre a classe trabalhadora, apesar de serem incorporados elementos como entrevistas, documentos históricos, críticas de cinema e outras fontes no trabalho de pesquisa, evita-se a busca de questões sobre a realidade objetiva que não estejam contidas na própria obra de arte. Em Viramundo (1965), por exemplo, o mais antigo e também o primeiro a ser analisado dentro do corpus da pesquisa, foi possível perceber que o diagnóstico do diretor Geraldo Sarno e sua equipe sobre as dificuldades encontradas por migrantes nordestinos em se adaptar ao ritmo e às regras guardava, como uma de suas principais referências, a visão desenvolvimentista da sociologia dos anos 1950 e 1960. Contudo as informações que nos ajudaram a entender a importância dessa referência para a realização do filme foram buscadas a partir do momento em que, no próprio filme, pudemos localizar termos, ideias, associações e referências que sugeriam essa relação entre debates teóricos e a própria narrativa fílmica, sendo esse procedimento não cotejado quando a correspondência não se mostrasse factível com o desdobramento das cenas, sequências e opções estéticas da obra.

\section{A especificidade da representação fílmica}

A relevância de manter a centralidade da obra nessa perspectiva de estudo justifica-se também no fato de a imagem do filme, em meio à riqueza de elementos sobre a realidade social que é capaz de destacar, já oferecer fontes suficientes para o start investigativo. Algo que pode ser percebido em Lukács (1982a), quando, ao analisar o caráter de desantropomorfização da imagem do filme, destaca as características fundamentais do cinema como expressão artística que representa ou refigura o mundo objetivo.

Lukács (1982a) aponta para três elementos singulares da linguagem cinematográfica, duas herdadas da fotografia, quais sejam, a dupla mimese e sua consequente desantropomorfização; e uma terceira propriamente fílmica, a captura da visualidade em movimento. Dessa forma, no processo criativo, o cinema apresenta diferenças em relação às artes plásticas e à arquitetura. Para Lukács (1982b), a "dupla mimese" seria a dupla refiguração da realidade objetiva na confecção da imagem do filme, constituída técnica e subjetivamente.

De um lado, como em todas as formas de arte, haveria uma intervenção criativa por meio da qual a inventividade do diretor ou realizador de cinema daria forma ao material das imagens com que trabalha. A ação de fundir planos, editar cenas e compor um enredo consistiria, nesse sentido, em um conjunto de operações necessárias à realização de um filme, mas não se diferenciaria, fundamentalmente, de outras atividades criativas.

Segundo Lukács (1982a), "desantropomorfizador" é todo o conhecimento em que vigora a "retransformação" numa relação entre indivíduos daquilo que, ideologicamente, se mostra na aparência como a forma fantasmagórica de uma relação entre coisas, sendo portanto, o espaço para uma espécie de esclarecimento ou desvelamento da forma ideológica e fetichizada com que a realidade objetiva é apreendida pela razão. Nele, a importância das relações entre os homens é a resposta como o resultado de sua ação no mundo, operando uma espécie de "desfetichização" - em uma concepção adaptada por Lukács (1982a) do pensamento de Marx para o âmbito estético -, pois a realidade social aparece como decorrente de relações recíprocas e mediadas pelo indivíduo. Nessa projeção, tal refiguração se 
mostra capaz de desvelar a dependência dessas objetividades diante das relações humanas e dos outros elementos da realidade e, assim, de realizar uma contraposição às tendências geradas pela ideologia.

Especificando o caráter da mimese no cinema, Lukács (1982a) reconhece o processo de "desantropomorfização" como protagonizado pela existência de uma "dupla mimese", ou dupla refiguração da realidade objetiva na constituição da imagem do filme. De um lado, como em todas as formas de arte, haveria uma intervenção criativa por meio da qual a inventividade dos diretores ou realizadores de cinema daria forma ao material das imagens com que trabalham. A ação de fundir planos, editar cenas e compor um enredo consistiria, nesse sentido, num conjunto de operações necessárias à realização de um filme capaz de revelar aos indivíduos seu papel nas relações sociais e materiais, mas não se diferenciaria fundamentalmente de outras atividades criativas e de suas potenciais capacidades "desfetichizadoras".

Por outro lado, nos casos especiais do cinema e da fotografia, haveria um momento da mimese desenvolvido, sobretudo, a partir das condições de funcionamento da aparelhagem técnica que dá origem à imagem. Ao ligar o aparelho, o registro que a fotografia e o cinema realizam do cotidiano tem o direcionamento de seu operador, do diretor de cinema ou ๗ do fotógrafo que guia seus ângulos. Quando a

${ }^{3} \mathrm{O}$ conceito de mimese é empregado por Lukács (1982a)

- nos volumes que compóem a Estética, para analisar a ma-

- neira como a obra de arte apresenta forma e conteúdo do

$\infty$ mundo em sua linguagem. A mimese corresponde a um

¿ processo de representação ou refiguração por meio do qual

- a obra incorpora elementos da realidade concreta para ga-

๗ื nhar forma, o que não ocorre sem que o sujeito imprima,

$>$ nesse processo, toda sua carga cultural e social. Embora o

s. próprio autor aponte para essa incorporação em mais de

- uma oportunidade como um tipo de "reflexo" da realidade,

$\stackrel{\pi}{\geq}$ dando a ideia de que a representação fílmica teria como

๘ూ uma de suas características fundamentais algum tipo de

- reprodução das condições objetivas do mundo para além

I da subjetividade artística - o que torna o uso do conceito

ช bastante problemático -, a referência que fazemos aqui

leva a mimese como uma categoria que não abandona o

elemento da mediação do sujeito, da sua subjetividade e

das suas condições sociais, sendo esta inclusive a abor-

J dagem mais recorrente no pensamento do próprio autor. há, junto ao direcionamento que o seu criador emprega, um dispositivo que faz o aparelho registrar tudo que está no ângulo da imagem a partir do ponto de perspectiva, sem que seu operador precise moldar, como na pintura, o todo e cada contorno que nela se apresenta. Tal procedimento permite, por exemplo, que um filme aponte, muitas vezes, para algo não previsto por seu realizador, ou que um fotógrafo capte traços e acontecimentos imprevisíveis ou não programados para ocupar os registros.

Esse duplo processo, que envolve tanto a subjetividade criadora quanto seu progresso técnico, foi reconhecido de formas relativamente semelhantes tanto por Kracauer (2010) quanto por Benjamin (2014). Ambos analisaram os sentidos humanos como produto histórico e perceberam o impacto da mimese fotográfica e cinematográfica sobre os processos que envolvem a percepção e a sensibilidade humana. Segundo Benjamin, o cinema teria trazido uma série de consequências no que se refere à forma de produção estética e sua posterior fruição. As possibilidades técnicas da reprodução da imagem e do som teriam, pela primeira vez, aproximado os indivíduos dos detalhes do mundo que nos cerca, e o cinema teria possibilitando esse aprofundamento da percepção. No mesmo sentido, Kracauer (2010) entendia como principal característica do cinema o caráter fotográfico, sendo bastante claro seu impacto para a experiência sensível nos novos tempos.

Embora, no processo de refiguração do cinema, esses dois momentos miméticos ocorram simultaneamente, Lukács (1982c) atribui certa preponderância ao modo de funcionamento técnico dos dispositivos de captação. Para o autor, essa característica não apenas introduz a singularidade da imagem do cinema, como também indica em que condições a realidade objetiva e as formações sociais serão levadas aos enredos e às narrativas dos filmes. No nosso entendimento, essa argumentação peca por excesso de ênfase na capacidade técnica de captação da objetividade. Ademais, en- 
tendemos também que há, na teoria do autor, demasiado determinismo da técnica sobre a capacidade criativa do artista. Ainda que seja clara a relação entre desenvolvimento técnico e processo criativo - pois a técnica pode, de fato, apresentar potencialidades -, caberá ao artista não só percebê-las, mas forjar as relações entre forma e conteúdo de sua obra.

A “desantropomorfização", por sua vez, é o modo como a imagem do filme capta os elementos dispostos na realidade exterior com igual valor de exposição, tendo isso um impacto direto no modo como os indivíduos serão inseridos nas circunstâncias que envolvem as cenas. Como indica Lukács (1982c) e também Béla Balázs (2010), se, nas artes narrativas, o indivíduo ocupava historicamente o centro dos enredos e histórias às quais a arte se reportava, no cinema, o mundo circundante que ele habita e que envolve a natureza, o ambiente animal e vegetal, e, sobretudo, os ambientes sociais forjados coletivamente aparecem com o mesmo valor de exposição da própria figura humana na imagem. "Mas o específico aqui é que ambos, homem e mundo, possuirão - tal como na vida cotidiana - exatamente o mesmo valor de realidade em sua exposição"4 (Lukács, 1982c, p. 185, tradução nossa).

Desse modo, no que se refere à exposição imagética da inter-relação do indivíduo com o mundo, o cinema representa o indivíduo e a natureza com o mesmo valor de exposição na imagem do filme, sendo essa equiparação e seu desdobramento por meio da imagem em movimento um elemento constitutivo da forma estética do filme.

O terceiro elemento a ser exposto é exclusivo do cinema: a captura da visualidade acompanhada pelo decurso do tempo. No filme, como podemos observar, a autenticidade originária da imagem ganha tempo e ritmo, seleção de momentos, organização, encadeamento etc., gerando uma aproximação ainda

4 "Pero lo específico aquí es que ambos, hombre y mundo, han de poseer - igual que en la vida cotidiana - exactamente el mismo valor de realidad en su aparecer" (Lukács, 1982c, p. 185). maior com o ritmo da vida cotidiana. Dado o caráter da continuidade visual ou da captura da imagem em movimento, o indivíduo não só percebe sua relação com a realidade material e a natureza à sua volta, como vê sua interação com os elementos da vida cotidiana se tornarem substrato imagético e narrativo. ${ }^{5}$

Como sustentava Marx (2003), o ser humano é, sobretudo, um ser social, determinado dialeticamente pelas condições materiais de existência e condicionado pelas formas de pensamento compartilhadas com os outros indivíduos. Por isso, no cinema, a captação dos elementos da relação dialética entre o cineasta e a realidade objetiva levaria sua forma de representação a contar com a possibilidade de analisar o produto dessa mediação, qual seja, o próprio filme, que traz em si uma refiguração que envolve a síntese das múltiplas determinações da produção artística e incluem, em seu interior, tanto a ideologia na qual se insere quanto, potencialmente, os elementos contraditórios do mundo.

Assim, a possibilidade de "refigurar" o indivíduo em interação com a vida cotidiana tanto exploraria, num sentido mais imediato, a dialética da relação do criador com seu entorno e os demais sujeitos sociais, quanto os termos em que se desdobra sua sociabilidade no interior de uma dada formação social. Seria, então, o desdobramento dessa dupla mimese que permite captar o decurso da vida cotidiana em movimento, de forma imagética, que poderíamos compreender a maneira pela qual os indivíduos e as tramas sociais são representados no filme. Enfim, o método de estudo da representação deve contemplar o diálogo entre esses elementos miméticos e a capacidade ex-

5 "No cinema [...], o momento do presente é, como sempre ocorre no decurso temporal real, um momento real de transição entre o passado e o futuro; normalmente, temos vivido já como presentes os momentos passados, que se fazem para nós passado diante de nós, e o presente vivenciado em cada caso era, ao menos a um segundo antes, um futuro ameaçador ou prometedor. Desse modo, os diversos momentos correspondem perfeitamente à proximidade da vida cotidiana; só a sua vinculação de conteúdo e, por conseguinte, formal, pode lhes dar uma significação superior a respeito da vida cotidiana” (Lukács, 1982c, p. 181-182, tradução nossa). 
pressiva da subjetividade artística, ${ }^{6}$ para, através dessa relação, podermos elaborar análises que compreendam o caráter representativo nos termos aqui propostos. ${ }^{7}$

Segundo Adorno (2008), para apreendermos o caráter da obra de arte, torna-se necessário investigar os laços com as condições sociais objetivas nas quais ela foi produzida, contemplando uma análise ao mesmo tempo formal e de seu conteúdo, em termos de suas singularidades. Em consonância com Adorno (2008), consideramos a criatividade do cineasta, no que diz respeito à sua capacidade artística de transcender a realidade e elaborar, através da arte, novos objetos no mundo. Essa criação contém, ao mesmo tempo, sua subjetividade e os elementos objetivos da realidade vivida, encarnando potências do próprio devir histórico.

Como percurso analítico, observamos a relação entre as características propriamente fílmicas das obras - tomadas, sequências, elementos de montagem audiovisual etc. (Casetti; Di Chio, 1991; Martin, 1990) - e as dimensões objetivo-subjetivas do filme para, relacionando com a realidade social, entender e explicar aquilo que estivera ao alcance da referida investigação sociológica. No decorrer das análises elaboradas acerca dos documentários aqui abordados evidenciaram-se formas de sociabio lidade, comportamentos ou, em suma, relações 污 dos personagens com o mundo. ${ }^{8}$ Tais elemen-

ᄅ ${ }^{6}$ Ainda que Marx não tenha se detido, de forma específica, ¿ sobre a arte e a criação artística, ele trata da subjetividade œ e da criatividade em diversos textos. Entre outros, indi-

† camos os capítulos sobre a crítica à dialética hegeliana e

p sobre propriedade privada e comunismo, nos Manuscritos

‘. Econômico-Filosóficos (Marx, 2009). Ver também Marx e

† Engels (2011).

م. 7 Para tanto, concordamos quando Marx afirma a autono-

œ mia relativa da arte, na medida em que há uma "relação

¿ desigual do desenvolvimento da produção material com,

i por exemplo, o desenvolvimento artístico" (Marx, 2011, p.

๓ 62), de forma que compreendemos os diversos aspectos da

$>$ sociedade em suas próprias relações prático-sociais, onde

ธิ a cultura ou a justiça, por exemplo, têm um desenvolvi-

T. mento desigual em relação à economia.

त 8 É importante ressaltar como, guardados os seus limi-

tes, essa perspectiva pode ser também aplicada a filmes

que não envolvam a existência recorrente de indivíduos

como personagens centrais. Afinal, como nota Béla Balázs

$\bigcirc$ (2010), o desenvolvimento da linguagem cinematográfica

está de tal maneira ligado à imagem de seres humanos

que, mesmo as panorâmicas de paisagens ou os filmes com

$\exists$ animais costumam promover cenas e efeitos que levam em tos se tornaram perceptíveis sobretudo a partir de seus conteúdos, significados e questões expressas nas imagens, nas sequências dialógicas, nas interações entre os personagens e o mundo material.

Ao investigar os filmes, observamos uma grande variação entre as formas de tematizar a classe trabalhadora. Nos documentários Viramundo e A opinião pública, migrantes nordestinos, operários, estudantes universitários e funcionários públicos estavam associados a um comportamento considerado alienado, incapazes de agir politicamente de forma organizada, tendentes à passividade e à subordinação. Segundo a literatura específica, tal comportamento foi majoritário até o final dos anos 1950. E, com a pesquisa, observamos a relativa permanência dessas características nos documentários estudados e um processo de alteração estética e política no decorrer dos anos 1970. Tal tendência foi observada em outras obras sobre o tema (Ramos, 2008; Silveira, 2006), ainda que houvesse, já na década de 1960, a experiência do Cinema Novo, que já conseguia estabelecer outro tipo de aproximação com os referidos grupos, enxergando, neles, a potência de se tornarem agentes de sua própria história.

Nos outros filmes, percebemos uma ênfase no cotidiano da classe trabalhadora, acompanhando suas greves, como em $A B C$ da greve (ABC..., 1990), ou recuperando os tempos de luta das Ligas Camponesas nos anos 1960, com Cabra marcado para morrer (Cabra..., 1984), seja em seu decurso, seja como memória dos personagens em tomadas feitas nos anos 1980. Ao analisar as estéticas empregadas no registro dessas lutas, tornou-se possível entender como ali se incorporaram, tardiamente, tanto algumas das premissas críticas e políticas do Cinema Novo quanto as inovações estilísticas do cinema verité e do direct cinema. Através dessa muconta as sensações e percepções de um interlocutor em potencial - como o registro de paisagens agradáveis aos olhos e de grandes dimensões, o acompanhamento em tom suave de animais interagindo ou ainda uma cena de ação marcada por um fenômeno climático. 
dança estilística, observou-se a incorporação temática do registro da classe trabalhadora como sujeito histórico no Brasil. No caso particular da nossa investigação, tornou-se o ponto de partida para o cotejamento de documentos históricos e ensaios teóricos que dialogavam com a ação política organizada da classe trabalhadora.

Sendo produto das próprias condições objetivas historicamente determinadas e de suas contradições intrínsecas, a representação artística contida em cada obra se apresenta, assim, como um momento particular da história do homem em geral, que compreende tanto a forma como o conteúdo estético impressos em sua expressividade. Considerando as particularidades específicas de sua produção, no nosso entender, sua análise nos permite um avanço na compreensão do ser humano acerca de si mesmo.

Todos os elementos que versam sobre a especificidade da imagem fílmica e o alcance da linguagem cinematográfica, como podemos observar, são necessários para a proposta de uma análise que se preste a compreender os elementos fundamentais de uma narrativa e o modo como ela representa seus objetos. A representação, nos filmes, do modo como os indivíduos, enquanto personagens, interagem com o espaço, nos leva a proposições sobre o desdobramento de manifestações de rua e ações organizadas em espaços públicos, modalidades de interação com a natureza e, sobretudo, como o trabalho, como ação transformadora no mundo, integra a sociabilidade humana. Foi o que observamos nas cenas da Greve de 1979 do ABC paulista, em $A B C$ da Greve, ou ainda a peculiar interação dos camponeses envolvidos com as lutas da Liga Camponesa de Sapé, na Paraíba, com os equipamentos de projeção utilizados pelo diretor Eduardo Coutinho, em Cabra marcado para morrer.

Por outro lado, não podemos deixar de notar que é a criação estética, sob a aparelhagem técnica desenvolvida a partir da realidade social, em termos dialéticos, e não a técnica em si, o impulso fundamental da forma estética na arte. Em consonância com Adorno (2008), consideramos a criatividade do cineasta como a capacidade artística de transcender a realidade e elaborar, através da arte, novos objetos no mundo, e essa criação contém, ao mesmo tempo, sua subjetividade e os elementos objetivos da realidade vivida, encarnando potências do próprio devir histórico.

\section{PROCEDIMENTOS METODOLÓGICOS}

Como apontam Francesco Casetti e Federico Di Chio (1991) em Cómo analizar un film, a análise fílmica pode ser entendida como um conjunto de operações aplicadas sobre um objeto determinado e consistente, a partir de um processo de decomposição e sucessiva recomposição, pautando-se no objetivo de identificar melhor os componentes, a arquitetura, os movimentos, as técnicas, a dinâmica ou, em síntese, os princípios de construção e funcionamento de um filme. Nesse exercício, a referida técnica nos permitiu, primeiramente, decompor o filme de acordo com o recorte proposto previamente - que, nesse caso, era o cotidiano dos trabalhadores - e, em seguida, atingir, a partir da recomposição, os princípios gerais de construção e produção de sentido nas obras acerca da temática investigada.

A técnica utilizada, como é possível observar, começa e termina no estudo da obra, embora não permaneça restrita a ela. Tanto durante a recomposição quanto no momento da escrita e sistematização dos dados, há reflexão acerca das relações entre a obra e a realidade social. Parte fundamental dessa decomposição é a decupagem fílmica propriamente dita, na qual os extratos dos filmes vão sendo sistematizados de acordo com as questões a serem abordadas e com o uso dos termos adequados no âmbito da linguagem cinematográfica. Nesse sentido, a montagem, a planificação, a angulação e os movimentos de câmera, que são os elementos específicos da linguagem cinematográfica, e também os não específicos, como 
a iluminação, a cor, o cenário, o vestuário, os personagens, etc., bem como todas as técnicas visuais e sonoras que compõem todo um vocabulário próprio do cinema - cena, sequência, mise en scène, argumento, enredo, etc. - são termos utilizados nesse momento para estabelecer uma descrição mais precisa e criteriosa das diversas partes que compõem uma obra cinematográfica, entendendo esses termos como critérios orientadores que variam conforme a obra e conforme a sua análise (Martin, 1990).

No caso do documentário, que constitui um gênero do cinema com uma forma narrativa particular, há ainda uma série de termos criados para descrever a maneira específica como esses elementos são empregados nesse gênero não ficcional. É o caso da voz over ou "voz de Deus", recurso no qual o narrador descreve uma cena sem estar presente no universo diegético, e da voz off, narração fora de campo de um personagem que está inserido na circunstância, mas se mantém fora do alcance das imagens. Também a noção de "circunstância de mundo no seu transcorrer", muito utilizada nesta pesquisa e que foi originalmente cunhada por Fernão Ramos (2005), consiste nas imagens que narram ou acompanham situações que estão ocorrendo naquele exato momento diante da câmera - sem ou com quase nenhuma intervenção da equipe -, sendo, portanto,

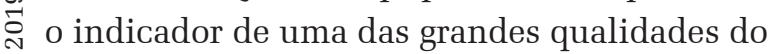
Фं cinema documentário: a de produzir registros sobre o desdobramento de fenômenos históricos exatamente no momento em que eles estão em culminância.

O procedimento de análise fílmica, todavia, compreende um trabalho maior do que apenas a seleção e descrição dos elementos específicos e não específicos dessa linguagem, luz da teoria do cinema. O momento de decomposição, cujo marco é um plano de análise responsável por introduzir e organizar o aprofundamento sobre o caráter social das temáticas abordadas no filme, orienta o modo como a recuperação das determinações da representação serão buscadas e, ao mesmo tempo, vai se remodelando a partir das descobertas e reflexões sobre a obra. Os planos contêm, dentre outras coisas, informações sobre: a) o contexto histórico em que o filme foi realizado; b) a circunstância histórica para qual aponta o filme; c) o marco teórico que será utilizado durante a investigação; e, por último, d) questões e passagens a vida social da classe trabalhadora a serem empregadas no estudo sociológico da representação dos filmes documentários. Nesse sentido, as informações que são coletadas nas primeiras aproximações com os filmes são sistematizadas e, dessa forma, servem de norte para o decorrer da pesquisa. No entanto, não raro novas questões e aspectos do filme vão sendo descobertos e novas referências, fatos históricos e discussões vão sendo incorporados, e, desse modo, vão compondo todo o rol de informações a reaparecer no processo de escrita para explicar as múltiplas determinações dos princípios gerais de construção e funcionamento de um filme.

A recomposição, por sua vez, que envolve a sistematização final de todas as informações e aspectos relevantes a serem levantados, representa um resultado do trabalho que foi possível realizar na decomposição. Nesse momento, além de ser extremamente crucial o uso dos termos técnicos adequados, já empregados na decupagem propriamente dita, realizando uma descrição ao máximo fiel ao que ocorre na imagem - além de guardarem-se as conclusões e considerações sobre as condições sociais que deram origem à representação para um momento posterior -, é importante também organizar a exposição da análise de maneira que esteja coerente com a proposta metodológica da pesquisa. No nosso caso, além de deixarmos as reflexões sobre os princípios de construção e funcionamento dos filmes para o final da discussão sobre cada obra em particular, amarrando na conclusão as reflexões mais gerais, optamos por organizar a análise em tópicos voltados para a contemplação da proposta metodológica. Tópicos de abertura das análises, como "Um passo à frente do cinema 
clássico" ou "A imagem como alicerce realista”, por exemplo, estavam dedicados a descrever traços da narrativa dos filmes, destacando passagens e traços importantes; enquanto itens finais, como "O migrante e a imagem do atraso" ou "O proletariado urbano e seu individualismo" traziam, para as análises, as considerações finais que poderíamos fazer sobre cada filme diante do recorte da classe.

É bem verdade que, no decorrer da pesquisa, as duas etapas sempre se misturam: quando se assiste aos filmes e se busca neles as questões a serem abordadas, há sempre uma sistematização que, em certo sentido, é involuntária, pois é praticada em meio à fruição da obra, mas também costuma vir acompanhada de anotações e esboços de apoio. Na fase da escrita final do texto, também é comum ocorrerem readequações, revisões de informações e pausas para a busca de novas referências para a análise de determinados assuntos. Todavia quanto mais o pesquisador consegue distinguir as duas fases em seu trabalho, mais substanciado e organizado deverá ser o resultado. Como as visões sobre as obras costumam mudar bastante à medida que nos aprofundamos sobre 0 caráter social objetivo de suas temáticas e de seu conteúdo, a reunião dessas referências com uma antecipação maior tende a contribuir para o esgotamento dos dados e informações que a investigação é capaz de ressaltar.

\section{CONSIDERAÇÕES FINAIS}

No texto El Logo de la Sociología, o sociólogo espanhol Salvador Giner (2004) ressalta que as ciências sociais tiveram historicamente mais sucesso tentando compreender como processos sociais acontecem do que formulando leis ou equações capazes de projetar com precisão regularidades históricas, sugerindo o porquê dos acontecimentos ou as razões para sua existência objetiva. A tentativa de conhecer algo sobre o acontecimento, ao invés de almejar descobrir as suas causas, tem se tornado o ideal de historiadores, arqueólogos, etnólogos e sociólogos, que pretendem, assim, enriquecer o repertório e os saberes de diversos aspectos da realidade com modelos interpretativos plausíveis, reforçados por categorias conceituais precisas capazes de fazer avançar o conhecimento sobre seu objeto.

Consoantes com essa orientação, acreditamos que a metodologia efetivamente aplicada à análise fílmica e que descrevemos nesta oportunidade nos levou a um caminho possível de apreensão e explicação dos modos como a classe trabalhadora foi representada na imagem do filme documentário no Brasil. No caso dos filmes exemplificados, sobretudo no que diz respeito ao período, que vai do início dos anos 1960 até meados dos anos 1980, por exemplo, mesmo após a conclusão de nossas análises empíricas, não nos pareceu possível responder a questões como: "Por que o cinema documentário não apontou para as lutas sociais da classe trabalhadora antes da Ditadura Militar?" Ou: "Qual o impacto do Golpe de 1964 para a produção cinematográfica documental do país?”.

Através da análise da representação do proletariado brasileiro no cinema documentário, notamos que as condições sociais e as contradições enfrentadas pelas frações da classe trabalhadora, entre os anos 1960 e 1980, foram um mote fundamental para o desenvolvimento estético do filme documentário brasileiro.

Contudo, representadas como passivas ou ativas, as frações de classe foram, em todo esse período, um objeto fundamental de preocupação dos roteiros de documentários, sendo os personagens dessa classe, suas condições materiais e seu comportamento as referências de um sujeito histórico que permitiu aos documentaristas repensarem a forma como realizavam o cinema e as condições socioculturais de seu próprio discurso.

Embora críticos da classe trabalhadora, filmes como Viramundo, Opinião pública e Maioria absoluta (1964) põem em xeque a população brasileira. Será também na década de 
1960, sobretudo a partir de reflexões como a de Glauber Rocha em Terra em transe (1967), que emerge a percepção de um cinema crítico, produzido por aqueles que integram a classe trabalhadora e se arvoram a criticá-la duramente. Já nos anos 1970, são revistas a impessoalidade e a neutralidade dos anos 1960, herdadas do documentarismo clássico. Tenta-se construir um documentarismo menos afeito à mera reprodução imagética de posicionamentos políticos e com mais espaço para a expressividade dos personagens.

Por fim, através da reconstituição dos traços das condições materiais de seus personagens ou da luta política "refigurada" nos filmes, essa metodologia nos pareceu satisfatória para compreender como a classe trabalhadora foi representada de maneira recorrente como um protagonista histórico. A partir da reflexão estética sobre os filmes e de dados exteriores às obras, coletados durante a revisão bibliográfica, percebemos como a relação dos cineastas com indivíduos e grupos sociais que apareceram de forma recorrente como mote dos movimentos de autocrítica e reflexão sobre o próprio trabalho de registro, nos indica como os sujeitos que aparecem nos filmes foram não só tematizados, mas apresentados como uma força político-social, tornando-se referência para o a inquietação dos cineastas e influenciando,

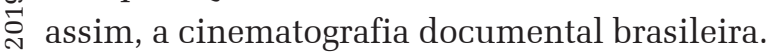

$>$ BALÁZS, B. L’homme visible et l'esprit du cinéma. U.E.: î Circé, 2010.

BASTIDE, R. Arte e sociedade. São Paulo: Companhia Editora Nacional, 1971. 250 p.

BENJAMIN, W. Obras escolhidas: um lírico no auge do capitalismo. 4. ed. São Paulo: Brasiliense, 1989. v. 3.

BENJAMIN, W. Estetica y politica. Buenos Aires: Los Cuarenta, 2014. 156 p. ISBN 978-987-1501-11-3.

BERNARDET, J.C. Cineastas e imagens do povo. São Paulo:
Brasiliense, 1985.

BISPO, B. V. B. Imagens de uma utopia latino-americana: a batalha do Chile, filme de Patrício Guzmán. Curitiba: Appris, 2019. ISBN 978-85-473-2442-1.

CABRA marcado para morrer. Produção de Eduardo Coutinho. Neuilly-sur-Seine: Gaumont, 1984.

CÂMARA, A. da S.; LESSA, R. O. Cinema documentário brasileiro em perspectiva. Salvador: EDUFBA, 2013. ISBN 978-85-232-1098-4

CÂMARA, A. da S.; SILVA, B. E. da; LESSA, R. O. Ensaios de Sociologia da arte. Salvador: EDUFBA, 2018. 260 p. ISBN 978-85-232-1784-6.

CASETTI, F. Les théories du cinéma depuis 1945. Paris: Nathan Université, 1999. 374 p. ISBN 978-2-09-190352-1.

CASETTI, F; DI CHIO, F. Cómo analizar un film. Barcelona: Paidós, 1991.

FLICK, U.; KARDOFF, E. Von; STEINKE, I. A Companion to qualitative research. London: SAGE, 2004. 452 p. ISBN 978-0-7619-7375-1.

FRANCASTEL, P. A realidade figurativa. São Paulo: Perspectiva, 2015. ISBN 978-85-273-0366-8.

GINER, S. El logo de la sociología. Interthesis, Florianópolis, V. 1 , n. $1,2004$.

JAMESON, F. O inconsciente político. São Paulo: Ática, 1999. ISBN 978-85-08-04273-9.

KRACAUER, S. Théorie du film: la rédemption de la réalité matérielle. Paris: Flammarion, 2010.

LESSA, R. O. Da passividade à luta política: as imagens da classe trabalhadora no cinema documentário brasileiro. 2015. 207 f. Tese (Doutorado em Ciências Sociais) Universidade Federal da Bahia, Salvador, 2015a.

LESSA, R. O. O conflito social no campo no cinema documentário brasileiro. Saarbrücken: Novas Edições Acadêmicas, 2015b.

LUKÁCS, G. Estética I: la peculiaridad de lo estético. Barcelona: Grijalbo, 1982a.

LUKÁCS, G. Estética II: problemas de la mímesis. Barcelona: Grijalbo, 1982b.

LUKÁCS, G. Estética IV: cuestiones liminares de lo estético. Barcelona: Grijalbo, 1982c.

MARTIN, M. Linguagem cinematográfica. São Paulo: Brasiliense, 1990.

MARX, K. Contribuição à crítica da economia política. Tradução de Maria Helena Barreiro Alves. São Paulo: Martins Fontes, 2003.

MARX, K. Manuscritos econômico-filosóficos. São Paulo: Boitempo Editorial, 2009. ISBN 978-85-7559-002-7.

MARX, K. Grundrisse: manuscritos econômicos de 18571858; esboços da crítica da economia política. Tradução de Mario Duayer, Nélio Schneider. São Paulo: Boitempo Editorial, 2011.

MARX, K.; ENGELS, F. A ideologia alemã: crítica da mais recente filosofia alemã em seus representantes Feuerbach, B. Bauer, Stirner, e do socialismo alemão em seus diferentes profetas, 1845-1846. São Paulo: Boitempo, 2011. ISBN 978-85-7559-073-7.

NAPOLITANO, M. A arte engajada e seus públicos (1955/1968). Revista estudos históricos, v. 2, n. 28, p. 103124, 25, fev. 2001.

NAPOLITANO, M. Esquerdas, política e cultura no Brasil (1950-1970): um balanco historiográfico. Revista do Instituto de Estudos Brasileiros, n. 58, p. 35-50, maio 2014 
OPINIÃO pública. Direção de Geraldo Sarno. [S.l.: S.n.], 1967.

PARANAGUA, P. A. (Ed.). Le cinéma brésilien. Paris: Centre Georges Pompidou, 1987.

RAMOS, F. P. (Org.). Teoria contemporânea do cinema: documentário e narratividade ficcional. São Paulo: Senac, 2005 .

RAMOS, F. P. Mas afinal... o que é mesmo documentário? 2. ed. São Paulo: Senac, 2008.

SEBBAH, E. Quand la sociologie des sciences se saisit de la sociologie de l'art. Sociedade e Estado, [S.l.], v. 20, n. 3 , p. 541-560, 2005. ISSN 0102-6992. DOI: 10.1590/S010269922005000300003.
SILVA, B. E. da. A representação da Modernidade em Dziga Vertov: estudo sociológico sobre o cinema soviético. [S.l.]: Novas Edições Acadêmicas, 2017.

SILVEIRA, W. da. Walter da Silveira: o eterno e o efêmero. Salvador: Oiti, 2006. v. 1

TERRA em transe. Direção Glauber Rocha. [S.l.]: Difilm, 1967.

VIRAMUNDO. Direção de Geraldo Sarno. [S.l.: S.n.], 1965. XAVIER, I. Alegorias do subdesenvolvimento: cinema novo, tropicalismo e cinema marginal. São Paulo: Editora Cosac Naify, 2014

ZOLBERG, V. L. Para uma sociologia das artes. São Paulo: Senac, 2006. 


\section{IMAGES OF THE WORKING CLASS IN THE BRAZILIAN DOCUMENTARY: methodological notes}

\author{
Antônio da Silva Câmara \\ Bruno Vilas Boas Bispo \\ Rodrigo Oliveira Lessa
}

\section{IMAGES DE LA CLASSE OUVRIÈRE DANS LE DOCUMENTAIRE BRÉSILIEN: notes méthodologiques}

\author{
Antônio da Silva Câmara \\ Bruno Vilas Boas Bispo \\ Rodrigo Oliveira Lessa
}

In this article, we return to methodological aspects of investigation on representations of working-class found in documentary cinema. Through discussion with based on concepts from Marx and other theorists such as Lukacs, Adorno, Benjamin, and Kracauer, we here seek to review the terms of this research experience from its proposal approach and deepen an approach to the concept of representation that contemplates the form and content aspects of the film as a work of art. In this way, we point to a correlation between representation and social reality, emphasizing the relevance of creative elements intrinsic to it. To this aim, we seek to analyze the film as a result of the determinations from the mutually mediated relationship between artists and social reality. Then, we seek to unfold such reflections in procedures analysis, exposing the use of such elements in the research cited, in order to contribute to the methodological reflections about sociology of art from the accumulated experience in our investigations.

Keywords: Sociology. Cinema. Documentary cinema. Methodology. Art.
Dans cet article, nous revenons aux aspects méthodologiques de notre recherche sur les représentations de la classe ouvrière dans le cinéma documentaire. À travers d'une discussion basée sur les concepts de Marx et d'autres théoriciens, tels que Lukács, Adorno, Benjamin et Kracauer, nous nous proposons à revoir les termes de cette expérience à partir d'une proposition méthodologique et à approfondir une approche du concept de représentation qui envisage des aspects de la forme et du contenu cinématographique en tant qu'œuvre d'art. Ainsi, nous soulignons la corrélation entre la représentation et la réalité sociale, surtout sur la pertinence des éléments créatifs qui lui sont intrinsèques. Pour cela, nous avons analysé le film comme un produit des déterminations résultant des rapports médiatisés entre les artistes et la réalité sociale. Ensuite, nous avons traduit ces réflexions en procédures d'analyse spécifiques, exposant l'utilisation de ces éléments dans la recherche citée, afin de faire des apports méthodologiques à sociologie de l'art à partir de l'expérience accumulé dans nos recherches.

Mots cLÉs: Sociologie. Cinéma. Cinéma documentaire. Méthodologie. L'art.

Antônio da Silva Câmara - Doutor em Sociologia. Professor do Departamento de Sociologia da (NUCLEART), desenvolvendo pesquisas na área de Sociologia da arte. Publicações recentes: Enjeux Evironnementaux et Tourismo au Brésil: le rôle de l'artesant em forêt Attlantique. Orgs. Agnès, CLERCRENAUD, Colette MÉCHIN, Antônio da Silva CAMARA, Lídia Maria Pires CARDEL; L’HARMATTAN, PARIS, 2019; Ensaios de Sociologia da Arte, EDUFBA. Orgs. Antônio da Silva CÂMARA; Bruno Evangelista da SILVA, Rodrigo Oliveira LESSA. 2018; Estudos socioambientais e saberes tradicionais do Litoral Norte da Bahia: diálogos interdisciplinares. Lídia Maria Pires CARDEL, Antônio da Silva CÂMARA, Colette MÉCHIN, Agnès CLERC-RENAUD. EDUFBA. Salvador. 2016.

Bruno Vilas Boas Bispo - Doutorando em Ciências Sociais no Programa de Pós-Graduação em Ciências Sociais da Universidade Federal da Bahia (UFBA). Doutorado Sanduíche na Universitat Autònoma de Barcelona (UAB). Membro do Núcleo de Estudos em Sociologia da Arte (NUCLEART), com sede na Faculdade de Filosofia e Ciências Humanas da UFBA. Autor do livro Imagens de uma utopia Latinoamericana: a batalha do Chile, filme de Patrício Guzmán (2019).

Rodrigo Oliveira Lessa - Doutor em Ciências Sociais pela Universidade Federal da Bahia (UFBA). Professor de Ensino Básico, Técnico e Tecnológico no Instituto Federal de Educação, Ciência e Tecnologia Baiano (IF Baiano), Campus Alagoinhas. Membro do Núcleo de Estudos em Sociologia da Arte (NUCLEART), com sede na Faculdade de Filosofia e Ciências Humanas da UFBA. Autor do livro O Conflito Social no Campo no Cinema Documentário Brasileiro: luta de classes e representação fílmica (2016) e um dos organizadores de Cinema Documentário Brasileiro em Perspectiva (2013) e Ensaios de Sociologia da Arte (2018). 
Antônio da Silva Câmara, Bruno Vilas Boas Bispo, Rodrigo Oliveira Lessa

ERRATA

CADERno CRH, Salvador, v. 32, n. 87, Set./Dez. 2019

No artigo IMAGENS DA CLASSE TRABALHADORA NO DOCUMENTÁRIO BRASILEIRO: apontamentos metodológicos, com número de DOI http://dx.doi.org/10.9771/ccrh.v32i87.32181, publicado no periódico Caderno CRH, vol. 32, nº 87: página inicial 491 - página final 504, nas páginas:

491:

Onde se lia:

"Bruno Vilas Boas Bispo Correio"

Leia-se:

"Bruno Vilas Boas Bispo"

504 - Coluna 1

Onde se lia:

"Bruno Vilas Boas Bispo Correio"

Leia-se:

"Bruno Vilas Boas Bispo"

504 - Coluna 2

Onde se lia:

"Bruno Vilas Boas Bispo Correio"

Leia-se:

"Bruno Vilas Boas Bispo" 